\title{
DECIFRA-ME OU TE DEVORO: A INQUIETANTE ESTRANHEZA NA ARTE CONTEMPORÂNEA
}

\author{
Juliana de Moraes Monteiro \\ doutoranda em Estética e Filosofia da Arte \\ bolsista CAPES
}

\begin{abstract}
Resumo:Nesse artigo, trata-se de analisar a atividade artística do nosso tempo por meio do conceito freudiano inquietante estranheza, tradução do termo alemão das unheimlich.Assim, seguindo uma chave de leitura proposta pelo filósofo italiano Giorgio Agamben em seu livro Estâncias, analiso esse problema tendo como base o episódio da Esfinge no mito de Édipo, narrativa na qual um enigma estranho e insolúvel é proposto. Pretende entender a obra de arte contemporânea como um enigma que tensiona as relações problemáticas entre significante e significado esmiuçadas por esses dois autores.
\end{abstract}

Palavras-chave: Agamben, Edipo, Arte Contemporânea, Estética.

\section{A inquietante estranheza: do Unheimlich de Freud à arte contemporânea}

A afirmação de Wöfflin segundo a qual nem tudo é possível em todas as épocas diz muito sobre como a arte contemporânea pôde encontrar na psicanálise uma importante fonte de material para o desenvolvimento de processos artísticos que surgiram bem próximo um dos outros. Para citar um caso óbvio desse período, é notável como os surrealistas viram na Interpretação dos sonhos de Freud as bases para seus posicionamentos estéticos.

Em um dos raros textos em que o psicanalista faz alusão à sua preocupação com a estética, Freud se volta não para investigar as formas de apreensão sensível do belo ou a contemplação do sujeito diante das obras de arte, tal como era característico do regime estético surgido cerca de dois séculos antes e fundado sobre os ideais da arte clássica.

Pelo contrário, no ensaio escrito em 1919 intitulado "Das Unheimliche" ( O estranho), Freud menciona um tipo de arte que suscitaria não prazer e 
deleite, mas sim sentimentos de angústia, estranheza e pavor, concluindo logo no início de sua análise que

nada em absoluto encontra-se a respeito deste assunto em extensos tratados de estética, que em geral preferem preocupar-se com o que é belo, atraente e sublime - isto é,com sentimentos de natureza positiva - e com as circunstâncias e os objetivos que os trazem àtona, mais do que com os sentimentos opostos, de repulsa e aflição. ${ }^{1}$

Dessa forma, o autor introduz o conceito unheimlich para dar conta desse tipo de experiência que teria sido negligenciada pelas teorias estéticas vigentes. $O$ estranho (ou a inquietante estranheza - l'inquiétant étrangeté - como os franceses optaram por traduzir) é um vocábulo que apresenta uma particularidade na língua alemã que o distingue de qualquer outra língua.

A partir da formação entre o prefixo negativo -un e a palavra que designa o seu oposto -heimlich ( familiar, doméstico, conhecido, íntimo, etc), o étimo unheimlich faz gravitar em torno dele um campo semântico complexo que diz respeito ao desconhecido, ao não-familiar, enigmático, ao oculto e estranho justamente por coincidir com o seu contrário e também poder ser familiar, conhecido e íntimo. Segundo Freud:

O que mais nos interessa nesse longo excerto é descobrir que entre os seus diferentes matizes de significado a palavra 'heimlich' exibe um que é idêntico ao seu oposto, 'unheimlich'.Assim, o que é heimlich vem a ser unheimlich. (Cf. a citação de Gutzkow: 'Nós os chamamos'unheimlich"; vocês o chamam "heimlich".') Em geral, somos lembrados de que a palavra'heimlich" não deixa de ser ambígua, mas pertence a dois conjuntos de idéias que, sem serem contraditórias, ainda assim são muito diferentes: por um lado significa o que é familiar,agradável e, por outro, o que está oculto e se mantém fora da vista. 'Unheimlich' é habitualmente usado, conforme aprendemos, apenas como o contrário do primeiro significado de 'heimlich', e não do segundo. Sanders nada nos diz acerca de uma possível conexão genética entre esses dois significados de'heimlich'. Por outro lado, percebemos que Schellingdiz algo que dá um novo esclarecimento ao conceito do Unheimlich, para o qual certamente não estávamos preparados. Segundo Schelling, unheimlich é tudo o que deveria ter permanecido secreto e oculto mas veio à luz. ${ }^{2}$

\footnotetext{
${ }^{1}$ FREUD, Sigmund. “O Estranho”, 1919. In: História de uma neurose infantil e outros trabalhos. Rio de Janeiro: Imago, 1996, p.137. ( Edição standard brasileira das obras psicológicas completas de Sigmund Freud, vol 17).

${ }^{2}$ Ibidem, p. 141.
} 
Sendo assim, o conceito de Freud mapeado nesse texto aparece como uma abertura para entender manifestações artísticas que começaram a surgir após o século XX deflagradas por Marcel Duchamp e chegam até os dias atuais desestabilizando uma série de pressupostos forjados por uma estética do belo, justamente aquela que Freud procurava provocar.

Se seguirmos a definição de Schelling do termo unheimlich, definição que Freud destaca como precisa para dar conta do conceito que, grosso modo, dizia respeito a algo que fora reprimido pelo sujeito e que continuaria operando na sua estrutura psíquica sendo sentido por ele por meio das sensações de angústica e inquietação enquanto algo estranhamente familiar, podemos vislumbrar na arte contemporânea um terreno fértil para pensá-lo.

Ao carcaterizar a relação do espectador com a obra de arte na contemporaneidade como sendo atravessada por um sentimento de desorientação, no qual nosso olhar não mais reconhece o lugar da obra, justamente porque essa topologia teria sido radicalmente alterada a partir do início do século XX. Como comenta Georges Didi-Huberman acerca dessa característica:

Freud propunha ainda um último paradigma para explicar a inquietante estranheza: é a desorientação, experiência na qual não sabemos mais o que está diante de nós e o que não está, ou então se - lugar para onde nos dirigimos já não é aquilo dentro do qual seríamos desde sempre prisioneiros. "Propriamente falando, o estranhamente inquietante seria sempre algo em que, por assim dizer, nos vemos totalmente desorientados. Quanto mais um homem se localiza em seu ambiente, tanto menos estará sujeito a receber coisas ou acontecimentosque nele produzem uma impressão de inquietante estranheza". ${ }^{3}$

Assim, tento entender uma certa estranheza da arte contemporânea a partir do momento em que as obras de arte passaram a ser incomprensíveis em sua maioria. Depois do gesto inaugural de Duchamp ao conceder à Fonte o estatuto de obra de arte, poderíamos entender a obra de arte como um enigma,

\footnotetext{
${ }^{3}$ DIDI-HUBERMAN, Georges. O que vemos, o que nos olha. São Paulo:Editora 34, 2010, p. 231. 
na qual as manifestações artísticas atraem e assumem o inquietante dentro de si mantendo o espaço do sentido em suspenso, sem nunca poder ser preenchido.

Nesse sentido, a forma esfíngica tipicamente egípcia que aparece como o monstro causador da peste no mitologema de Édipo pode ser sintomática para pensar o que está em jogo na arte contemporânea, um campo na qual perguntas sem respostas ou respostas para o qual não houve pergunta se entrelaçam em diversas obras de arte.

Desse modo, podemos dizer que o mal-estar frente às formas artísticas que qualquer espectador ou artista contemporâneo vivencia nos museus e galerias atuais pode ser descrita como a peste que assombra Tebas. E devemos nos perguntar: por que experiências tão terríveis, dolorosas que suscitam asco e pavor passaram a ser legitimadas como artísticas no século XX? Colocando esta indagação em termos psicanalíticos, poderíamos nos perguntar : qual é o recalque primário da arte contemporânea? O que estava velado e, de súbito, irrompeu como algo estranho e enigmático?

\section{O retorno do reprimido: arte contemporânea e o efeito egípcio}

Além das duas referências fundamentais deste artigo - Agamben e Freud - podemos ver na filosofia de Hegel um importante modo de analisar essa questão. Em seus Cursos de Estética, o filósofo alemão divide a história da arte em três grandes grupos de formas artísticas: a forma de arte simbólica, a forma de arte clássica e, por fim, a forma de arte romântica. Segundo o pensador acerca dessa divisão:

A arte simbólica procura realizar a união entre a significação interna e a forma exterior, que a arte clássica realizou essa união na representação da individualidade substancial que se dirige à nossa sensibilidade, e que a arte romântica, espiritual por essência, a ultrapassou. ${ }^{4}$

Para Hegel, os desdobramentos históricos das três formas de arte se deram a partir do momento em que existiu uma arte autêntica que foi superada

\footnotetext{
${ }^{4}$ HEGEL, G.W.F. Cursos de Estética volume II. Trad. Marco Aurélio Werle e Oliver Tolle. São Paulo: Editora da Universidade de São Paulo, 2014,p. 340.
} 
pelos ideais da arte clássica e esta tendo sido subsumida na arte romântica, teria desaparecido. A filosofia seria então o estágio de superação de todas as artes que nela se transformariam.

Longe de apontar um apreço pela teleologia hegeliana, interessa a essa texto a consideração de Hegel segundo a qual haveria uma arte antes do que a estética nos acostumou a pensar como um início, um mundo que não pudesse ser capturado pelo regime estético, com outras práticas discursivas que foram solapados para dar lugar a uma outra coisa.

Desse modo, para que a arte grega, de onde deriva a matriz de todo o pensamento estético que alcança sua plena formulação na modernidade, pudesse emergir foi preciso que se retirasse dela tudo que ela possuía de egípcio. A arte egípcia seria uma arte simbólica por excelência na qual a inadequação e um alheamento entre conteúdo e forma seria patente.

Ao contrário dela, a arte grega clássica traz a consciência do simbólico e garante um perfeito ajuste entre o significante e o significado, que despojados de um sentido enigmático vago e confuso caminha em direção ao desvelamento, e não a um cifrar e esconder tão familiares da cultura egípcia.

Em Agamben, o pensamento acerca de Hegel e do mal-estar da civilização ocidental frente aos símbolos encontra-se liberto com as considerações freudianas sobre a cisão no discurso entre uma palavra obscura e recalcada no inconsciente e outra cuja clareza se dá no nível da consciência. Para o filósofo italiano, o episódio entre Édipo e a Esfinge seria crucial para entender essa mudança de paradigma:

Uma fenda na linguagem, que terá vasta descendência matafísica: por um lado, o discurso simbólico e por termos impróprios da Esfinge, cuja essência é um cifrar e um esconder, e, por outro aquele claro, e por termos próprios de Ėdipo, que é um expressar e um decifrar.(...) Toda interpretação do significar como relação de manifestação e de expressão (ou, inversamente, de cifra e ocultamento) entre um significante e um significado (e tanto a teoria psicanalítica quanto a semiótica da linguagem pertencem a essa espécie) situa-se necessariamente sob o signo de Édipo, enquanto, pelo contrário, se põe sob o signo da Esfinge toda teoria do símbolo que, recusando tal modelo, dirige sua atenção sobretudo para a barreira entre 
significante e significado, a qual constitui o problema de toda significação. ${ }^{5}$

Assim, para Agamben é preciso repensar a forma como interpretamos as relações de significação bem como é preciso recolocar o problema da estetização da arte. Para o filósofo, a arte não é uma atividade de ordem estética e sim ética e política.

Nesse sentido, a arte contemporânea expõe o fracasso de uma compreensão estética na medida em que deixa claro o limite atingido pelas formas de arte que longe de exibirem clareza, significados totalizantes ou harmonia e beleza, revelam, na contemporaneidade, a face aterrorizante da perda das categorias que orientavam a práxis artística e aa impossibilidade de se definir qualquer conteúdo, processo definido pelo teórico Mario Perniola justamente como "efeito egípcio". Como coloca Perniola:

O efeito egípcio implica a passagem de uma estética europeia de derivação grega a uma estética que encontra os próprios modelos em outras civilizações pré-clássicas e extraeuropeias. Isso comporta a dissolução de muita oposições $(. . .)^{6}$

$\mathrm{Na}$ arte contemporânea, assistimos à derrocada dos conceitos fundadores da estética moderna paulatinamente e isso nos obriga, enquanto estudiosos, a rever o estatuto do próprio conceito de arte a buscar novas maneiras de nos relacionar com o desconhecido e oculto que emerge no nosso tempo.

Neste artigo, busco cruzar a inquietante estranheza proposta por Freud como um novo e autêntico modo de lidar com as obras de arte que causam desconforto, medo e pavor no mundo contemporâneo. Dessa forma, busquei na análise de Agamben acerca do mito de Édipo uma abordagem pautada pela primazia do ponto de vista da esfinge na medida em que ela funciona como uma alegoria para pensar os ciframentos oblíquos frente às significâncias transparentes.

\footnotetext{
${ }^{5}$ AGAMBEN, Giorgio. Estâncias: a palavra e o fantasma na cultura ocidental. Trad. Selvino José Assman. Belo Horizonte: Editora UFMG, 2007, p. 223.

${ }^{6}$ PERNIOLA, Mario. Enigmas: egípcio, barroco e neobarroco na sociedade e na arte. Chapecó, SC: Argos, 2009, p123.
} 
Ao associar uma à outra, busco interpretar a obra de arte contemporânea como um enigma que põe em jogo o estranhamento do qual Schelling fornecia uma definição precisa, afirmando, portanto, que a obra de arte contemporânea é unheimlich (estranha) justamente por ser o retorno de algo reprimido ao longo da história da arte. Desse modo, o que Freud nos mostra perfeitamente é que o reprimido nunca cessa de operar e surge em um dado momento em elementos patológicos ou mal-sucedidos na linguagem, mas que todavia são constitutivos e fundamentais para a vida do sujeito.

Traçando um paralelo, o que a obra de arte contemporânea - esse reprimido que retorna em formas problemáticas - revela é a possibilidade de forjar um outro projeto de relação com a obra de arte, passagem que pode ser seminal para pensar a arte como uma atividade ética e política e não estética.

\section{Decifra-me ou te devoro: arte contemporânea e o ter lugar do enigma}

Em uma frase conhecida, um dos arautos da história da arte, Erwin Panofsky, escrevera que deveríamos olhar as imagens da arte como se olha um velho conhecido ao cruzar a rua e que, ao nos identificar, levantaria o chapéu para nós em cumprimento. Na iconologia panofskyana fica claro a figura do historiador/filósofo ou crítico que mantém um relacionamento com as obras de arte nas quais elas devolvam uma certa paz e quietude a respeito do mundo que nos cerca.

Para Panofsky, as imagens artísticas espelhariam uma realidade na qual o sujeito se sente em perfeita harmonia frente aos símbolos e não diante do mal-estar. Traçando um paralelo, seria como se fóssemos convidados pela Esfinge a decifrá-la sem correr o risco de sermos devorados por ela. Contrapondo-se a isso, o filósofo francês Didi-Huberman, ao recorrer a Freud, aponta um lado muito mais afim com a arte contemporânea do que o modelo panofskyano de interpretação das imagens:

Mas o mundo das imagens jamais se constituiu com a única finalidade de fazer boa figura para uma história ou um saber a ser constituído sobre elas. Muitas imagens - mesmo aquelas com as quais desde séculos nos encontramos familiarizados - agem como o 
enigma cujo exemplo Freud introduziu a propósito do trabalho de figurabilidade: elas correm despenteadas, o chapéu voando no ar, às vezes correm mesmo sem cabeça... ${ }^{7}$

São essas obras de arte com o chapéu voando no ar ou sem cabeça que nos interessa pensar aqui. Na arte contemporânea, uma série de práticas demandam não um desvelamento ou uma solução, mas solicitam permanentemente que seja resguadado o lugar do enigma, tal como as esfinges egípcias não se ancoravam na exigência de um significado claro ou uma resolução, mas buscavam apenas expor uma autêntica forma de dizer, exibindo a linguagem cindida e fraturada em sua estrutura.

Se a Esfinge do mito de Édipo se atira de um penhasco ao se ver derrotada é porque já se instaurava para o mundo grego um outro regime discursivo, no qual a linguagem seria concebida como a phoné semantiké aristotélica.

Por fim, no que diz respeito à construção de nova relação com a arte contemporânea sob o ponto de vista da Esfinge, o melhor que podemos considerar é que se obra de arte não decifrada não levanta o chapéu ou nos devora, estamos, na verdade, a salvos.

\section{REFERÊNCIAS BIBLIOGRÁFICAS}

AGAMBEN, Giorgio. Estâncias: a palavra e o fantasma na cultura ocidental. Trad. Selvino José Assman. Belo Horizonte: Editora UFMG, 2007

DIDI-HUBERMAN, Georges. Diante da imagem: questão colocada nos fins de uma história da arte.São Paulo: Editora 34,2013. p. 239 . O que vemos, o que nos olha. São Paulo:Editora 34, 2010

FREUD, Sigmund. História de uma neurose infantil e outros trabalhos. Rio de Janeiro: Imago, 1996(Edição standard brasileira das obras psicológicas completas de Sigmund Freud, vol 17)

HEGEL, G.W.F. Cursos de Estética volume II. Trad. Marco Aurélio Werle e Oliver Tolle. São Paulo: Editora da Universidade de São Paulo, 2014

\footnotetext{
${ }^{7}$ DIDI-HUBERMAN, Georges. Diante da imagem: questão colocada nos fins de uma história da arte.São Paulo: Editora 34,2013. p. 239.
} 
PERNIOLA, Mario. Enigmas: egípcio, barroco e neobarroco na sociedade e na arte.Chapecó, SC: Argos, 2009 